\title{
Simulation of fuel consumption and emissions in typical traffic circumstances in Belgium
}

\author{
L. Pelkmans ${ }^{1}$, T. Denys ${ }^{1}$, E. Verhaeven ${ }^{1}$, G. Spleesters ${ }^{1}$, S. Kumra ${ }^{2}$ \\ \& A. Schaerf ${ }^{3}$ \\ ${ }^{1}$ VITO, Belgium \\ ${ }^{2}$ NetPEM, India \\ ${ }^{3}$ University of Udine, Italy
}

\begin{abstract}
During the execution of the project Floating Automotive Data Collection (FADC), various traffic conditions were recorded using in-vehicle measurements. A series of reference measurements were performed on a fixed route in Belgium in real traffic circumstances, including motorway, rural and city traffic. Three vehicles were used for the reference measurements: a passenger car, a delivery van, and a delivery truck. An on-board device recorded vehicle speed and GPS position on second-basis. The resulting speed profiles were used as input in the vehicle emission simulation programme VeTESS to estimate fuel consumption and emissions of certain vehicles driving according to these speed profiles. The goal of these calculations was to quantify the effect of preventing traffic jams. From the simulations it was concluded that a reduction in average speed does not necessarily lead to higher fuel consumption. Actually when average speed is reduced from speeds above $100 \mathrm{~km} / \mathrm{h}$ down to 80 or $60 \mathrm{~km} / \mathrm{h}$, fuel consumption can even be expected to decrease. Of course traffic jams are more about low average speeds. The simulations showed that when average speed drops below 30 or $40 \mathrm{~km} / \mathrm{h}$, fuel consumption increases significantly. Emissions of $\mathrm{NO}_{\mathrm{x}}, \mathrm{CO}$ and $\mathrm{HC}$ also increase in this case. So concerning fuel consumption and emissions it is indeed worth the effort to prevent traffic jams and slow traffic and to improve the traffic flow. The role of traffic jam detection is very important to take measures to improve the traffic flow and this way save fuel and reduce emissions.
\end{abstract}

Keywords: vehicle emissions, real traffic conditions, GPS recordings, emission simulation. 


\section{Introduction}

\subsection{FADC project}

The project Floating Automotive Data Collection (FADC) is carried out with the support of the EU-Asia Information Technology and Communications (IT\&C) Programme [1]. The project involves three partners: VITO in Belgium, the University of Udine in Italy and NetPEM (Network for Preventive Environmental Management) in India [2].

The main activities in the project envisage the calibration of the fleet management functionalities of a mobile and in-built vehicle device to local requirements in India. Activities include dynamic floating data collection, quantification of fuel consumption and pollutant emissions related to traffic conditions, organization of dedicated workshops and development of a reference framework for pilot applications in specific types of roads in New Delhi, India.

\subsection{Vehicle tracking and traffic jam detection}

In its early stage, tracking devices were very useful to locate stolen vehicles. However functionalities can be expanded very far. Built-in functions can be added and extra sensor signals can be added to the standard registrations [2]. Especially fleet management solutions are envisaged currently. With the use of intelligent transport systems, service companies can provide live traffic data, picked up from sensors that monitor vehicle speed, combined with incident reports. The tracking device can be in direct contact with a central server or can send regular reports and data.

Within this project the idea of combining a tracking device with automated traffic jam detection was looked into.

The idea was to monitor speeds and acceleration profiles as a function of location, and automatically detect deviations from normal fluent traffic. The detection could be done on-board the vehicle and in case of traffic jam detection, the device would send a message to a central server which maps different traffic jam detection massages. The system would of course operate optimal if a sufficient number of vehicles in the traffic are equipped with such device.

\section{Reference measurements}

As a basis for feeding the database with typical speed profiles as a function of specific roads and road types, reference measurements were performed on a fixed route in Belgium. Comparable measurements were afterwards performed in New Delhi, India.

For the measurements in Belgium, a route between VITO (Mol) and Antwerp was defined. The route has different parts of rural, city and motorway traffic. Figure 1 shows the route and its segments on a map. 


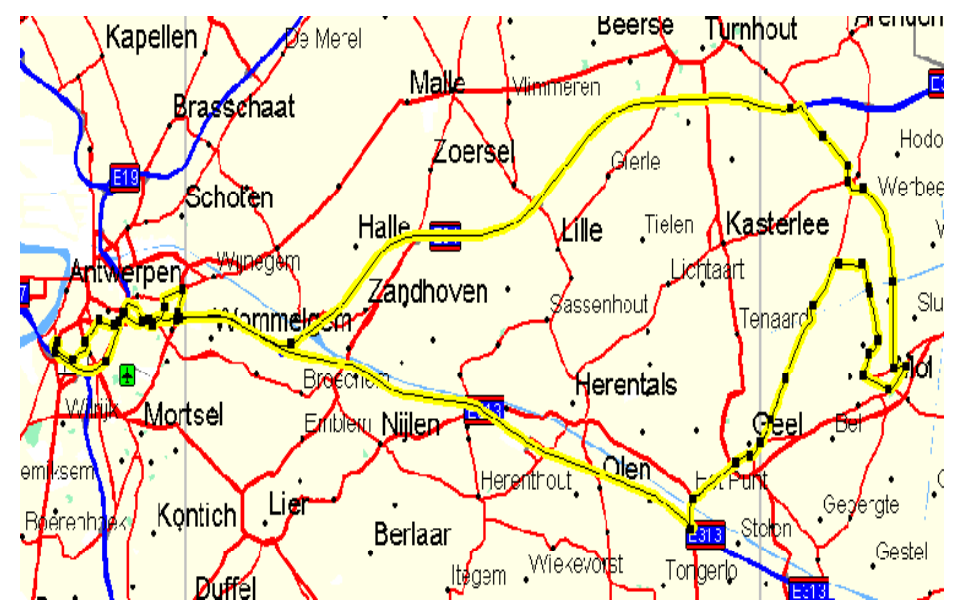

Figure 1: Test route with different road types.

11 segments were defined in the route, with typical traffic circumstances:

- Segment 1 (rural traffic around Mol): variation of average speed between 32 and $58 \mathrm{~km} / \mathrm{h}$. Variations are due to standstill at crossroads or some other traffic. No real effect of traffic jams.

- $\quad$ Segment 2 (city traffic in Mol): variation of average speed between 23 and $41 \mathrm{~km} / \mathrm{h}$. Variations are due to standstill at crossroads or some other traffic. No real effect of traffic jams.

- Segment 3 (rural traffic from Mol to Oud-Turnhout): variation of average speed between 35 and $54 \mathrm{~km} / \mathrm{h}$. Variations are due to standstill at crossroads, some other traffic or temporary road obstructions. No real effect of traffic jams.

- Segment 4 (motorway traffic on E34 from Oud-Turnhout to Antwerp): variation of average speed between 58 and $117 \mathrm{~km} / \mathrm{h}$. Especially the last part $(11 \mathrm{~km})$ from the merge of E34 with E313 in Ranst to Antwerp is sensitive for traffic jams.

- Segment 5 (motorway traffic on Antwerp Ring road): variation of average speed between 20 and $97 \mathrm{~km} / \mathrm{h}$. Ring road is very sensitive for traffic jams.

- $\quad$ Segment 6 (city traffic in Antwerp): variation of average speed between 8 and $26 \mathrm{~km} / \mathrm{h}$. Mind that the historic centre of Antwerp was not included, most was suburb traffic. Traffic flow here is very dependent on traffic circumstances. A lot of stand-still is recorded (between 10 and $30 \%$ of segment time).

- Segment 7 (rural traffic around Antwerp): variation of average speed between 20 and $40 \mathrm{~km} / \mathrm{h}$. This part also belongs to the surroundings of Antwerp and traffic flow also depends on the traffic circumstances.

- Segment 8 (motorway traffic on E34 from Antwerp to Geel): variation of average speed between 87 and $109 \mathrm{~km} / \mathrm{h}$. Traffic jams do not occur frequently in this part. 
- $\quad$ Segment 9 (rural traffic around Geel): variation of average speed between 21 and $41 \mathrm{~km} / \mathrm{h}$. Very busy connection between E313 and Geel. Most standstill at crossroads and roundabouts.

- $\quad$ Segment 10 (city traffic in Geel): variation of average speed between 22 and $37 \mathrm{~km} / \mathrm{h}$. Variations are due to standstill at crossroads or some other traffic. No real effect of traffic jams.

- Segment 11 (rural traffic from Geel to Mol): variation of average speed between 59 and $70 \mathrm{~km} / \mathrm{h}$. Very calm traffic.

Measurements were performed with

- $\quad$ a passenger car (Peugeot 206 Diesel)

- $\quad$ a delivery van (Ford Transit)

- $\quad$ a delivery truck (Mercedes Atego)

Not all recorded segments have the same sensitivity to traffic jams or slowdown traffic. To visualize this, figure 2 shows all recorded average speeds on the different segments.

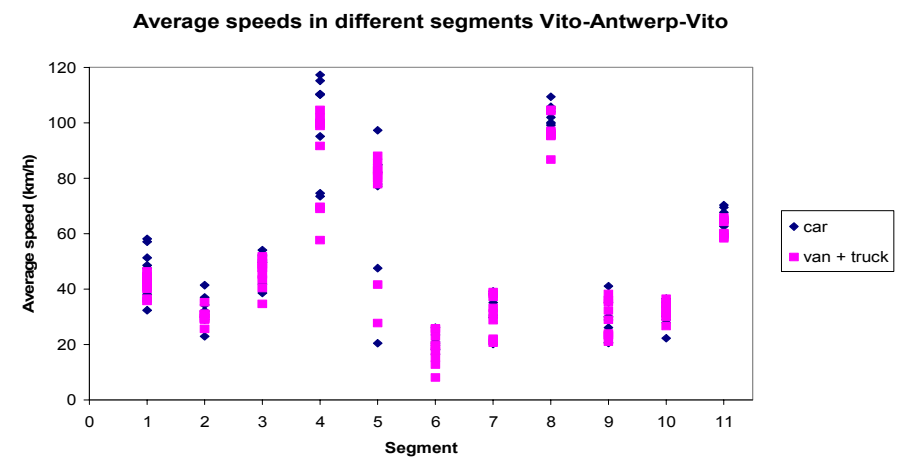

Figure 2: $\quad$ Average speeds recorded on the 11 segments.

\section{Simulations}

To quantify the effect of traffic circumstances on fuel consumption and exhaust gas emissions of vehicles, the recorded speed profiles were used as input in a vehicle emission simulation tool, called VeTESS.

\subsection{VeTESS}

The simulation tool VeTESS was developed within the Decade project, supported by the EC 5th Framework Programme [3]. The model can estimate fuel consumption and emissions of specific vehicles in specific journeys. The tool uses as input: the vehicle parameters, specified driver behaviour and the speed profile which the vehicle wants to achieve. 
Typical speed profiles can be derived either from on-road data, either from predictions of traffic models. The emission simulation tool can then be used to estimate fuel consumption and emissions on these speed profiles.

Within the Decade project specific vehicle and engine models were made to be used in VeTESS. The following vehicle models were used for the calculations in FADC:

$\begin{array}{ll}\text { - } & \text { VW Golf 1.9 TDi diesel passenger car }(1320 \mathrm{~kg}) \\ \text { - } & \text { Vitroën Jumper 2.5D diesel delivery van }(1890 \mathrm{~kg}) \\ \text { - } & \text { IVECO Eurocargo diesel delivery truck }(7500 \mathrm{~kg}) \\ \text { - } & \text { MAN A12 Euro 2 diesel bus }(12750 \mathrm{~kg}) \\ \text { - } & \text { Van Hool A600 Euro } 2 \text { diesel bus }(12000 \mathrm{~kg})\end{array}$

Typical vehicles weights and typical driving behaviour were assumed.

Emissions and fuel consumption of the passenger cars were simulated on the cycles driven by the Peugeot 206. For the delivery van the cycles of the Ford Transit were used. For the truck and the buses the cycles of the Mercedes Atego and the Ford Transit were used.

All cycles were divided into the 11 predefined segments.

It turned out that average speed is a very important parameter to relate fuel consumption and emissions to. In the following sections the relation of average speed with energy demand, fuel consumption and emissions of $\mathrm{NO}_{\mathrm{x}}, \mathrm{CO}, \mathrm{HC}$ and PM will be highlighted.

\subsection{Energy demand}

Energy demand is expressed in $\mathrm{kJ} / \mathrm{km}$. It is calculated with air resistance, rolling resistance, gradients (not counted in these simulations as the route is quite flat), and acceleration. Negative values of energy demand are not counted, as no brake energy can be recuperated (as in electric vehicles).

In most cases higher average speeds have higher average energy demand. Most of it has to do with the higher air resistance at higher speeds. At lower average speeds there is much variation in energy demand, depending on standstill time, number of stops, frequent accelerations, speeds that are reached.

The buses have a much higher weight than the other vehicles, and accelerations are therefore very important in the energy demand of buses. For the buses only at very high speeds there is a significant increase of average energy demand due to air resistance.

\subsection{Fuel consumption}

Fuel consumption and $\mathrm{CO}_{2}$ emissions are directly related, so only fuel consumption will be discussed here.

It would be expected that the higher the energy demand, the higher fuel consumption. This is only partly true. At higher speeds, the engine usually reaches better energy efficiency, which partly compensates the higher energy 
demand. The fraction of no or low load is much higher when average speed goes down, so energy efficiency also drops.

In the figures two effects are clear:

- Below a certain speed (30 or $40 \mathrm{~km} / \mathrm{h}$ ) there is an increase in fuel consumption due to a lower energy efficiency at low load (or a high fraction of idling).

- Above a certain speed $(100 \mathrm{~km} / \mathrm{h}$ for the cars and $80 \mathrm{~km} / \mathrm{h}$ for the heavier vehicles) the impact of air resistance becomes very important, leading to an increase of fuel consumption at higher speeds.

Of course all depends on the engine technology, but the two effects are clear for all vehicles. When looking at the difference between the diesel passenger car and the petrol car, the effect of low average speed is much more pronounced for the petrol car. The reason is that the efficiency of a petrol engine drops much faster in part load than for a diesel engine.

When average speed on motorway drops from 120 or $100 \mathrm{~km} / \mathrm{h}$ to values around $60 \mathrm{~km} / \mathrm{h}$, this usually does not increase fuel consumption, on the contrary. However real traffic jams, with standstill and low speed traffic (below $30 \mathrm{~km} / \mathrm{h}$ ), are usually at lower level speeds. In this case fuel consumption will clearly rise. So measures which lower average speeds at motorways to e.g. $80 \mathrm{~km} / \mathrm{h}$ (like "block-driving" in Belgium) aiming to avoid traffic jams are also very efficient for fuel saving.
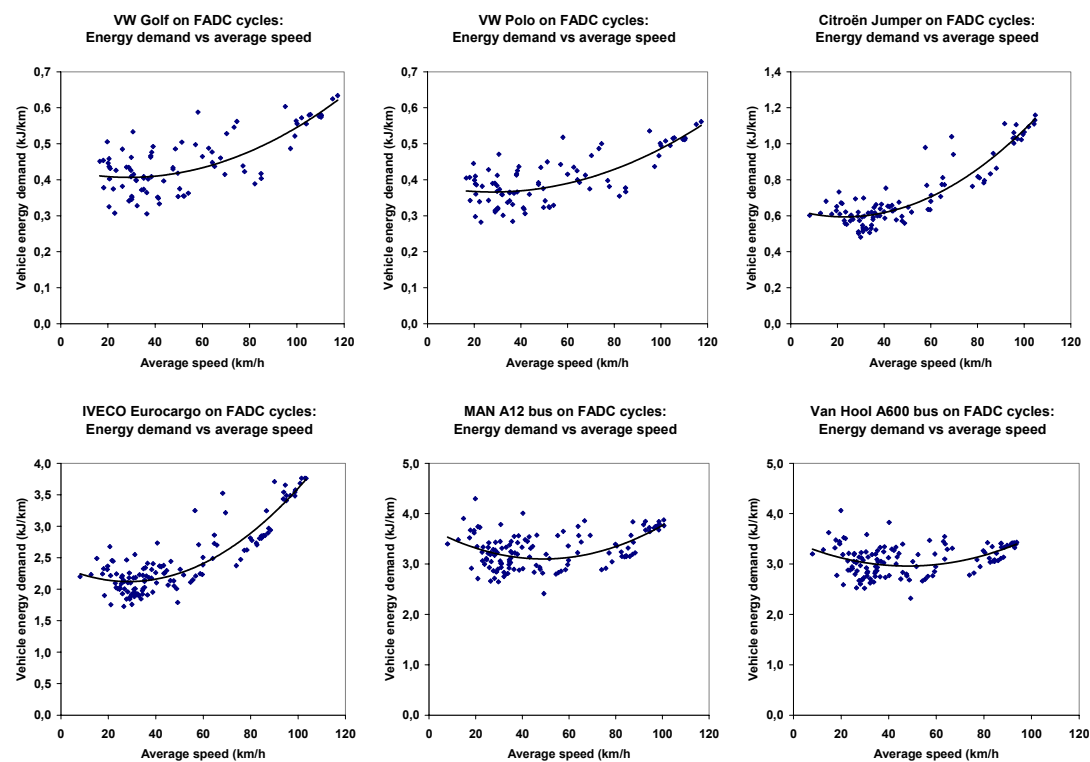

Figure 3: Energy demands calculated for the various recorded speed profiles as a function of average speed. 

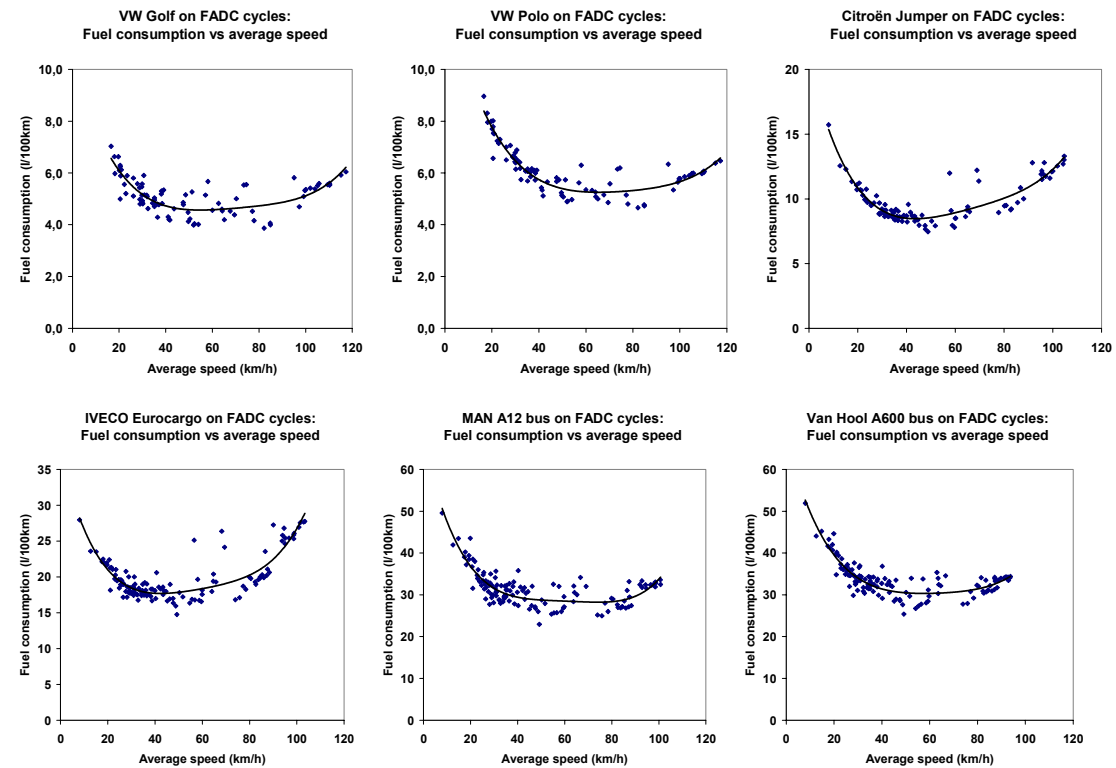

Figure 4: Fuel Consumption calculated for the various speed profiles as a function of average speed.
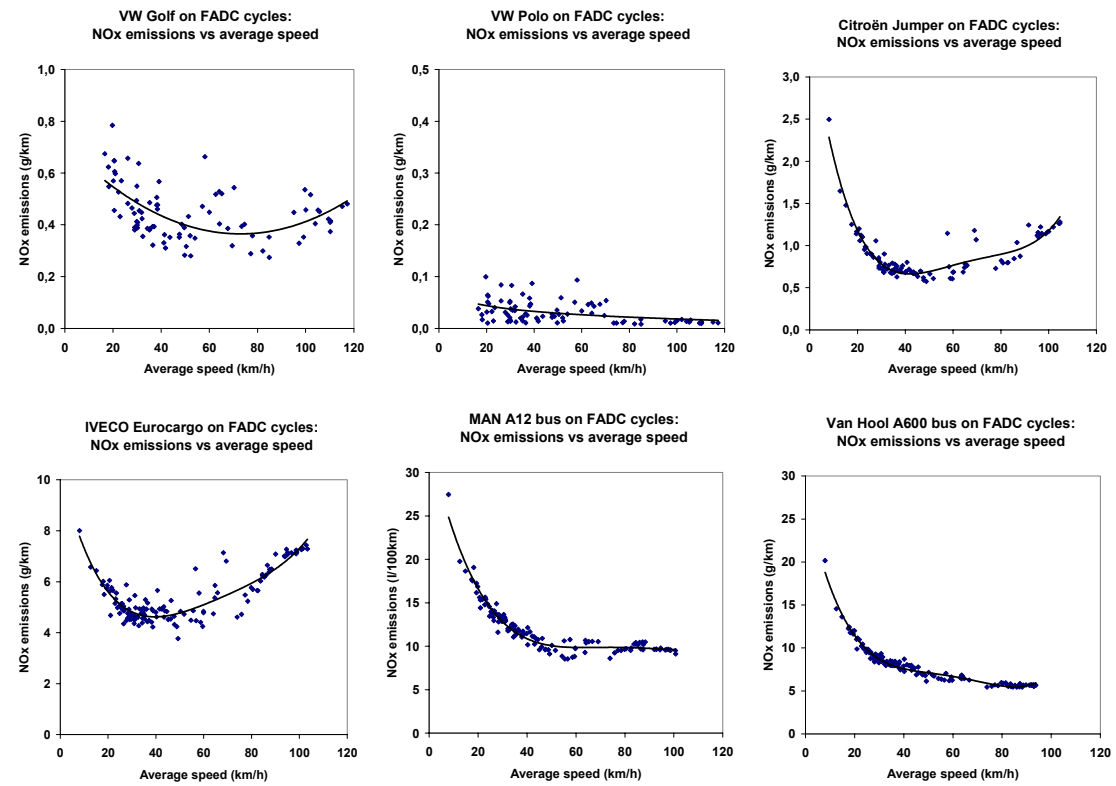

Figure 5: $\quad \mathrm{NO}_{\mathrm{x}}$ emissions calculated for the various speed profiles as a function of average speed. 


\subsection{Emissions}

$\mathrm{NO}_{\mathrm{x}}$ emissions are related to engine load, but some engine control effects (like EGR) do play a role. For gasoline engines there is the presence of a three-way catalyst which is most important for $\mathrm{NO}_{\mathrm{x}}$ reduction, so the effect there is different, and $\mathrm{NO}_{\mathrm{x}}$ emissions are generally much lower than for diesel vehicles. Concerning the diesel vehicles, in the following graphs it is clear that the increase in $\mathrm{NO}_{\mathrm{x}}$ emissions at lower average speed is much more pronounced than for fuel consumption. Below average speeds of $30 \mathrm{~km} / \mathrm{h}$ there is a substantial increase of average $\mathrm{NO}_{x}$ emissions.

Above certain speeds, again there can be an increase of $\mathrm{NO}_{\mathrm{x}}$, however less pronounced than for the lower speeds.

While $\mathrm{NO}_{\mathrm{x}}$ emissions for the gasoline car are much lower than for diesel cars, for $\mathrm{CO}$ emissions it is totally different.

The high speed effect is much less for CO emissions; at lower average speeds there is a clear increase of $\mathrm{CO}$ emissions, especially when looking at the results for the buses and the truck.
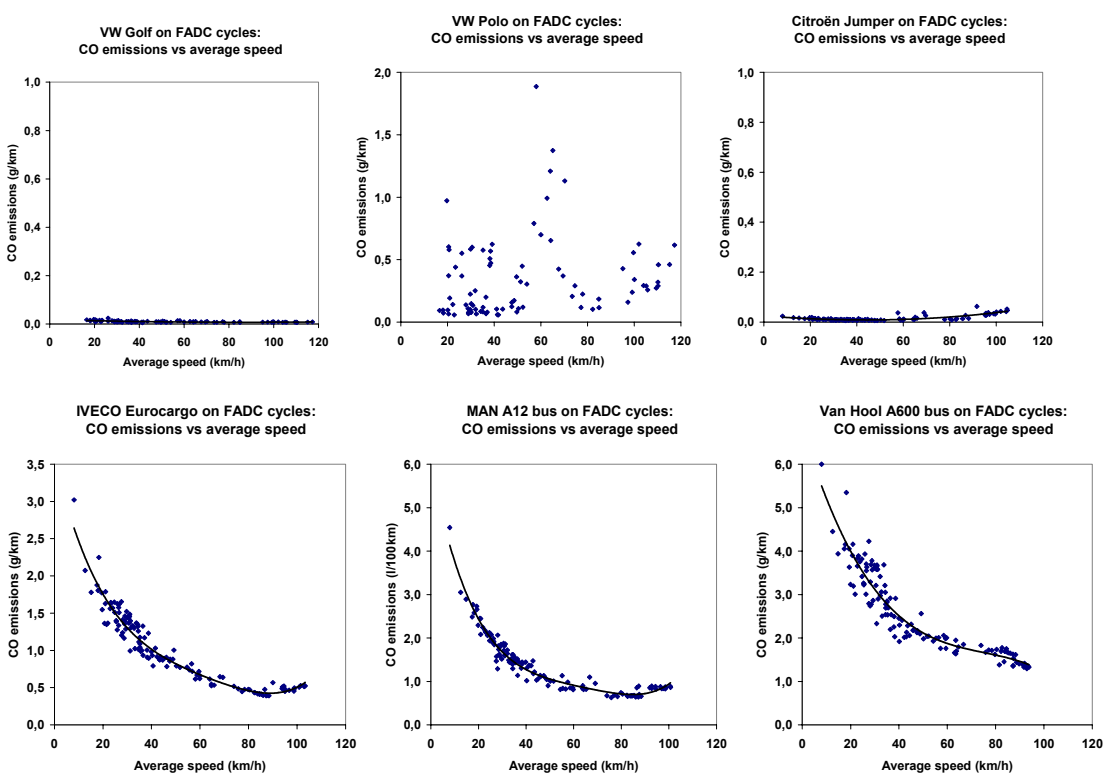

Figure 6: $\mathrm{CO}$ emissions calculated for the various speed profiles as a function of average speed.

For $\mathrm{HC}$ emissions conclusions are similar to $\mathrm{CO}$, so graphs are not included here.

The effect of lower average speeds is less pronounced for PM emissions. Overall some increase of PM at lower speeds can be noticed. 

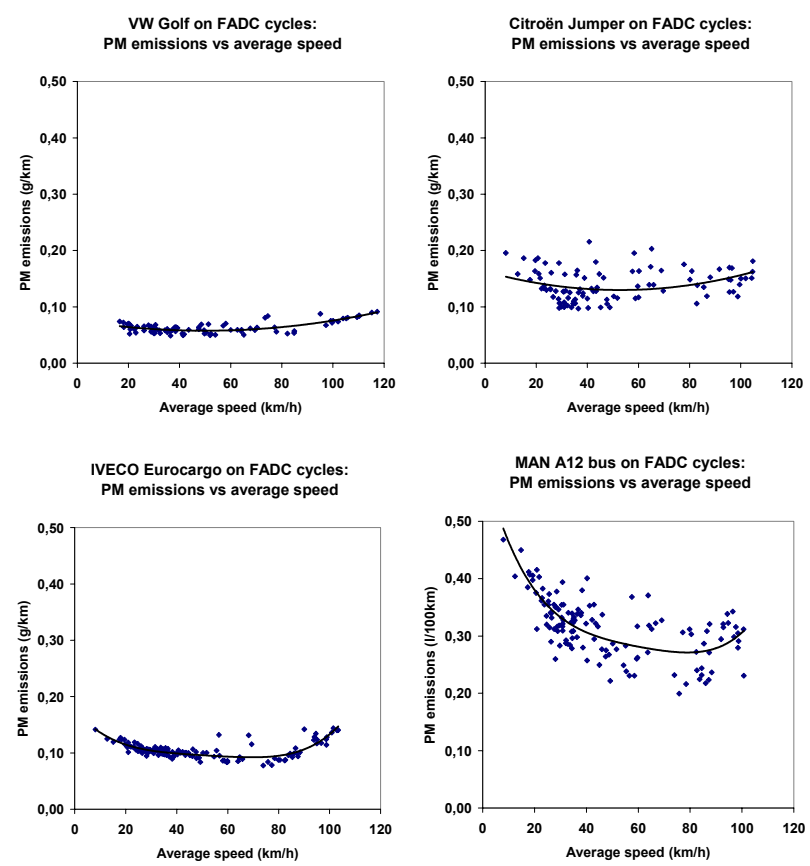

Figure 7: PM emissions calculated for the various speed profiles as a function of average speed.

\section{Conclusion}

From the simulations it was concluded that a reduction in average speed does not necessarily lead to higher fuel consumption. Actually when talking about high speeds (above $100 \mathrm{~km} / \mathrm{h}$ ), fuel consumption rises with higher average speeds.

When talking about traffic jams, it is the low average speeds which matter. When dropping below 30 or $40 \mathrm{~km} / \mathrm{h}$ in average speed, it was indeed noticed that fuel consumption increases significantly. Emissions of $\mathrm{NO}_{\mathrm{x}}, \mathrm{CO}$ and $\mathrm{HC}$ also increase when speed drops below 30 or $40 \mathrm{~km} / \mathrm{h}$.

Concerning fuel consumption and emissions it is indeed worth the effort to prevent traffic jams and slow traffic and to improve the traffic flow.

The role of traffic jam detection is very important to take measures to improve the traffic flow and this way save fuel and reduce emissions.

\section{Acknowledgements}

The authors want to acknowledge the partners co-operating in the FADC project, and also the Asia IT\&C Programme of the European Commission for their support. 


\section{References}

[1] Website of the Asia IT\&C Programme of the European Commission: http://europa.eu.int/comm/europeaid/projects/asia-itc/cf/index.cfm

[2] Website of the FADC project: www.vito.be/FADC

[3] Pelkmans L., P. Debal, T. Hood, G. Hauser, M.R. Delgado (2004): Development of a simulation tool to calculate fuel consumption and emissions of vehicles operating in dynamic conditions. SAE2004-011873, SAE 2004 Spring Fuels \& Lubricants, Toulouse, France, 8-10 June 2004 